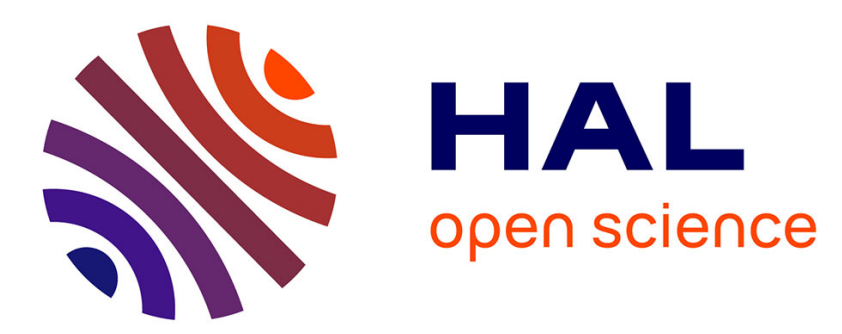

\title{
A Pediococcus strain to rescue honeybees by decreasing Nosema ceranae-and pesticide-induced adverse effects
}

\author{
Elodie Peghaire, Anne Moné, Frédéric Delbac, Didier Debroas, Frédérique
}

Chaucheyras-Durand, Hicham El Alaoui

\section{- To cite this version:}

Elodie Peghaire, Anne Moné, Frédéric Delbac, Didier Debroas, Frédérique Chaucheyras-Durand, et al.. A Pediococcus strain to rescue honeybees by decreasing Nosema ceranae-and pesticideinduced adverse effects. Pesticide Biochemistry and Physiology, In press, 163, pp.138-146. 10.1016/j.pestbp.2019.11.006 . hal-02359078

\section{HAL Id: hal-02359078 \\ https://hal.science/hal-02359078}

Submitted on 12 Nov 2019

HAL is a multi-disciplinary open access archive for the deposit and dissemination of scientific research documents, whether they are published or not. The documents may come from teaching and research institutions in France or abroad, or from public or private research centers.
L'archive ouverte pluridisciplinaire HAL, est destinée au dépôt et à la diffusion de documents scientifiques de niveau recherche, publiés ou non, émanant des établissements d'enseignement et de recherche français ou étrangers, des laboratoires publics ou privés. 


\title{
Journal Pre-proof
}

A Pediococcus strain to rescue honeybees by decreasing Nosema ceranae- and pesticide-induced adverse effects

Elodie Peghaire, Anne Moné, Frédéric Delbac, Didier Debroas, Frédérique Chaucheyras-Durand, Hicham El Alaoui

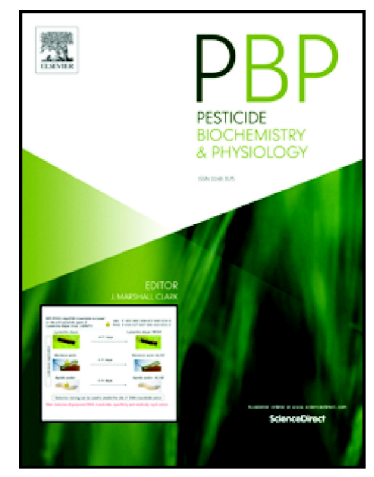

\author{
PII: $\quad$ S0048-3575(19)30489-4 \\ DOI: $\quad$ https://doi.org/10.1016/j.pestbp.2019.11.006 \\ Reference: $\quad$ YPEST 4486 \\ To appear in: $\quad$ Pesticide Biochemistry and Physiology \\ Received date: $\quad 6$ August 2019 \\ Revised date: $\quad 28$ October 2019 \\ Accepted date: $\quad 6$ November 2019
}

Please cite this article as: E. Peghaire, A. Moné, F. Delbac, et al., A Pediococcus strain to rescue honeybees by decreasing Nosema ceranae- and pesticide-induced adverse effects, Pesticide Biochemistry and Physiology (2019), https://doi.org/10.1016/ j.pestbp.2019.11.006

This is a PDF file of an article that has undergone enhancements after acceptance, such as the addition of a cover page and metadata, and formatting for readability, but it is not yet the definitive version of record. This version will undergo additional copyediting, typesetting and review before it is published in its final form, but we are providing this version to give early visibility of the article. Please note that, during the production process, errors may be discovered which could affect the content, and all legal disclaimers that apply to the journal pertain.

(C) 2019 Published by Elsevier. 


\section{A Pediococcus strain to rescue honeybees by decreasing Nosema ceranae-} and pesticide-induced adverse effects.

Elodie Peghaire ${ }^{\mathrm{a}}$, Anne Moné ${ }^{\mathrm{a}}$, Frédéric Delbac ${ }^{\mathrm{a}}$, Didier Debroas ${ }^{\mathrm{a}}$, Frédérique ChaucheyrasDurand $^{\mathrm{b},{ }^{*}} \quad$ fchaucheyrasdurand@lallemand.com and Hicham El Alaoui ${ }^{\mathrm{a},{ }^{*}}$ hicham.el_alaoui@uca.fr

aUniversité Clermont Auvergne, CNRS, Laboratoire Microorganismes : Génome et Environnement, F-63000 CLERMONT-FERRAND, France

${ }^{\mathrm{b}} \mathrm{R} \& D$ Animal Nutrition, Lallemand, Blagnac, France

${ }^{*}$ Corresponding authors at: Laboratoire Microorganismes: Génome et Environnement - 1 Impasse Amélie Murat - TSA 60026 - CS 60026 - 63178 Aubière Cedex - France. 


\section{Abstract}

Honeybees ensure a key ecosystemic service by pollinating many agricultural crops and wild plants. However, since few decades, managed bee colonies have declined worldwide. This phenomenon is considered to be multifactorial, with a strong emphasis on both parasites and pesticides. Infection by the parasite Nosema ceranae and exposure to pesticides can contribute to adverse effects, resulting in a perturbation of the honeybee physiology. We thus hypothesized that probiotic treatment could be promising to treat or prevent these disturbances. The aim of this study was to evaluate the effects of probiotics on $N$. ceranaeinfected and intoxicated honeybees (by the insecticide thiamethoxam and the fungicide boscalid). For this purpose, experiments were conducted with five probiotics. Among them, Pediococcus acidilactici (PA) showed the best protective effect against the parasite and pesticides. PA significantly improved the infected honeybee lifespan as prophylactic and curative treatments (respectively 2.3 fold and 1.7 fold). Furthermore, the exposure to pesticides induced an increase of honeybee mortality compared with the control group $(p<0.001)$ that was restored by the PA treatment. Despite its beneficial effect on honeybee lifespan, the PA administration did not induce changes in the gut bacterial communities (neither in abundance or diversity). N. ceranae and the pesticides were shown to deregulate genes involved in honeybee development (vitellogenin), immunity (serine protease 40, defensin) and detoxification system (glutathione peroxidase-like 2, catalase), and these effects were corrected by the PA treatment. This study highlights the promising use of PA to protect honeybees from both pathogens and pesticides.

Keywords: Honeybee, Nosema, pesticides, Pediococcus, probiotics 


\section{Introduction}

Honeybees are valuable resources worldwide at both ecological (contribution to biodiversity by pollination) and economical (crop pollination) levels. However, since several years ago, a decline of managed European honeybee (Apis mellifera) populations has been reported in Europe and in the United States (Potts et al., 2010; vanEngelsdorp and Meixner, 2010). This decline involves both biotic (pathogens and parasites) and/or abiotic (pesticides and pollutants) stressors. Numerous studies have shown that a wide variety of pesticides including insecticides, fungicides and herbicides can be found in honeybees and hive matrices (pollen, honey and wax) affecting these non-target organisms even at sublethal doses (Jabot et al., 2016; Kasiotis et al., 2014; Lambert et al., 2013; Mullin et al., 2010; Simon-Delso et al., 2015). Among them, boscalid is a fungicide belonging to the carboxamide family used in agriculture to control phytopathogenic fungi. As the primary action of boscalid is the inhibition of succinate dehydrogenase of the respiratory chain (Avenot and Michailides, 2007), this fungicide can affect honeybees by decreasing ATP concentration but also pollen consumption and protein digestion (Degrandi-Hoffman et al., 2015). The use of neonicotinoids, which are neurotoxic systemic insecticides, in intensive agriculture imposes a serious threat to honeybees. Neonicotinoids are agonists of acetylcholine receptors and consequently can impact the central nervous system of insects (Casida and Durkin, 2013). The chronic consumption of neonicotinoids like thiamethoxam led to lethal and sublethal effects on honeybees by altering sensory, cognitive and/or motor functions (Henry et al., 2015). Interestingly, combined exposure to sublethal doses of neonicotinoids and the intestinal parasite Nosema ceranae has shown a significant decrease of honeybee survival (Aufauvre et al., 2012; Dussaubat et al., 2016; Vidau et al., 2011). N. ceranae is an obligate intracellular pathogen of honeybee gut, associated with a decrease of honeybee lifespan 
(Alaux et al., 2010; Aufauvre et al., 2014, 2012; Goblirsch et al., 2013; Higes et al., 2008; Vidau et al., 2011). This parasite also induces sublethal effects including damages of the peritrophic membrane and impairment of gut renewal (Dussaubat et al., 2012; GarcíaPalencia et al., 2010; Panek et al., 2018), energetic and nutritional stress (Alaux et al., 2010; Mayack and Naug, 2009), hormonal disturbances (Dussaubat et al., 2010) and immune depletion (Alaux et al., 2010; Antunez et al., 2009). The only known reliable treatment to fight Nosema is the terpenoid fumagillin but its use has been forbidden in Europe since 2012. The honeybee midgut is the main site of both pesticide absorption and $N$. ceranae infection. Therefore, the gut microbiota could be disturbed by these stressors alone or in combination leading to gut dysbiosis. Honeybee gut microbiota is dominated by five ubiquitous bacterial species (Snodgrassella alvi, Gilliamella apicola, Lactobacillus Firm-4, Lactobacillus Firm-5 and Bifidobacterium asteroidetes) called "core microbiota" and four species less prevalent (Frischella perrara, Bartonella apis, Parasaccharibacter apium and Gluconobacter sp.) (Moran et al., 2012). Gut microbiota benefits were highlighted at several levels: nutritional (digestion and metabolism of complex molecules as lignin, synthesis of vitamins, fatty acids and amino acids) (Engel et al., 2012), immune system (barrier effect by biofilm formation, antimicrobial peptide production) (Martinson et al., 2012; Vásquez et al., 2012) and functional levels (homeostasis with insulin and vitellogenin signalling) (Zheng et al., 2017). Gut dysbiosis could therefore affect honeybee health (Corby-Harris et al., 2014; Cox-Foster et al., 2007; Leonhardt and Kaltenpoth, 2014). Administration of selected microorganisms, in this dysbiotic context, could thus represent beneficial microbes that could be used as probiotics. If probiotics are commonly used in vertebrates (Crotti et al., 2012), few studies have focused on their impact on honeybee health (Audisio et al., 2015; Baffoni et al., 2016; El Khoury et al., 2018; Gaggìa et al., 2018; Ptaszyńska et al., 2016). 
In the present study, the first experiment was conducted to evaluate the potential of five yeast or bacterial candidates for their anti-N. ceranae activity. For this purpose, each strain was chronically administered to honeybees. The probiotics were supplied in the sucrose syrup two days before infection by $N$. ceranae to evaluate their prophylactic/preventive effects. The second experiment was then conducted with a strain of Pediococcus acidilactici (PA) selected from the first experiment to investigate a possible "curative" effect on $N$. ceranae infection. In this aim, we administered the PA strain two days after infection. The experiment was broadened to investigate whether this PA strain could also have a beneficial effect on bees co-exposed to low doses of two pesticides, the insecticide thiamethoxam and the fungicide boscalid. RNAs were extracted from honeybees midguts to evaluate the effects of these different treatments on the gut microbiota composition (high throughput sequencing) and on the midgut transcriptional changes (qPCR) of selected genes involved in immunity, antioxidant system and gut development.

\section{Materials and Methods}

\section{Honeybee rearing and experimental procedures}

A mixture of emerging honeybees from three $A$. mellifera colonies (genotype Buckfast) of the same apiary (UMR 6023, Clermont Auvergne University, Clermont-Ferrand, France) was used for both experiments. Frames of sealed brood were placed in incubators $\left(33^{\circ} \mathrm{C}\right.$ with $60 \%$ relative humidity). Emerging honeybees were collected directly on the frames and distributed in Pain-type cages into groups of 50 individuals. Five queen's mandibular pheromones were mimicked by addition of a $5 \mathrm{~mm}$ piece of PseudoQueen ${ }^{\circledR}$ (Contech Enterprises Inc., Victoria, Canada) in each cage. Honeybees were maintained in incubators 
for 22 days and were fed with $50 \%$ sucrose syrup $(\mathrm{w} / \mathrm{v})$ complemented with $1 \%(\mathrm{w} / \mathrm{v})$ nutritional supplement (Provita' Bee, ATZ Dietetic, Mas-Cabardès, France).

The first experiment (Exp.1, figure 1A) was conducted with eight experimental groups: (i) uninfected and untreated honeybees (Ctrl.1), (ii) N. ceranae-infected honeybees (Inf.1), (iii) N. ceranae-infected honeybees treated with fumagillin (InfFum.1), (iv) N. ceranae-infected honeybees treated with Saccharomyces cerevisiae (InfSC.1), (v) N. ceranae-infected honeybees treated with Saccharomyces boulardii (InfSB.1), (vi) N. ceranae-infected honeybees treated with Lactobacillus plantarum (InfLP.1), (vii) N. ceranae-infected honeybees treated with Bacillus pumilus (InfBP.1) and (viii) N. ceranae-infected honeybees treated with Pediococcus acidilactici (InfPA.1). Strains were added in the sucrose syrup from the first day (D0, emergence until the end of the experiment) to evaluate their preventive effect on the infection. Honeybees were collectively infected with $10^{4}$ spores/bee for two days from two days after emergence (D2). The fumagillin treatment $(1 \mu \mathrm{g} / \mathrm{mL})$ started two days after the infection (D4) and maintained until the end of the experiment (D22) (figure 1A).

The second experiment (Exp.2, figure 1B) was conducted with six experimental groups : (i) uninfected and untreated honeybees (Ctrl.2), (ii) uninfected honeybees treated with Pediococcus acidilactici (PA.2), (iii) N. ceranae-infected honeybees (Inf.2), (iv) N. ceranaeinfected honeybees treated with Pediococcus acidilactici (InfPA.2), (v) honeybees exposed to both thiamethoxam and boscalid (ThBo.2) and (vi) honeybees exposed to both thiamethoxam and boscalid and treated with P. acidilactici (ThBoPA.2). In this experiment, infection was performed 2 days after emergence (D2), the treatment with pesticides started 4 days after emerging (D4 until the end of the experiment) and probiotics were given 4 days after infection (D6) (figure 1B). Honeybees were fed ad libitum with sucrose syrup 
complemented or not with probiotics or pesticides according to their experimental group. The feeders were replaced every $48 \mathrm{~h}$. Both the mortality and the sucrose consumption were monitored daily.

In the first experiment, infected honeybees were treated with $1 \mu \mathrm{g} / \mathrm{mL}$ of fumagillin as antimicrosporidial reference treatment. For intoxication experiments, honeybees were chronically exposed to low concentrations of thiamethoxam $(1.5 \mu \mathrm{g} / \mathrm{L})$ and boscalid (100 $\mu \mathrm{g} / \mathrm{L})$. Stock solutions were prepared in DMSO and diluted in sucrose syrup at a final concentration of $0.1 \%$. Honeybees from the infected and control groups were fed with $0.1 \%$ DMSO-containing sucrose. The pesticide consumption was monitored daily by measuring sucrose consumption that was reported to the remaining bees in each cage and expressed as "ng/bee/day".

\section{Microbiota establishment}

In order to mimic the microbiota in honeybee digestive tract in the hive, a procedure based on Powell et al. (Powell et al., 2014) was used in the second experiment. For this purpose, 66 foragers were collected from each hive, gut and rectum were dissected and crushed in 150 $\mu \mathrm{L}$ of PBS before to be added to the syrup at day 0,2 and 4 in each cage. In addition, to encourage a transfer of microbiota by trophallaxis to the emerging bees, three foragers from sampled colonies were collected, anaesthetized with $\mathrm{CO}_{2}$, marked with a paint dot on the thorax and placed in each cage.

\section{Nosema ceranae infection procedure}

N. ceranae spores were obtained according to Roussel et al. (Roussel et al., 2015) and stored at RT during less than two months. The spore concentration was determined by counting on hemacytometer and $N$. ceranae species was confirmed by PCR according to the procedure described previously (Martín-Hernández et al., 2007). Honeybees were collectively infected 
two days after the emergence with a dose of $10000 \mathrm{~N}$. ceranae spores per bee in the sucrose solution. At the end of the experiment (D22), abdomens of five honeybees per cage were dissected to evaluate the spore load according to Paris et al. (Paris et al., 2017).

\section{Probiotic candidate strains and culture}

Strains were provided by Lallemand SAS (Blagnac, France) including (i) two yeasts, Saccharomyces cerevisiae (SC CNCM I-1077) and Saccharomyces boulardii (SB CNCM I-1079), (ii) three Gram-positive bacteria, the homofermentative Pediococcus acidilactici (PA CNCM MA18/5M), the heterofermentative Lactobacillus plantarum (LP CNCM MA18/5U) and Bacillus pumilus (BP AQP 4275).

Microbial strains were grown in liquid media and $100 \mu \mathrm{L}$ of culture broth were daily sub cultured in $5 \mathrm{~mL}$ of their respective media and incubated at their optimum temperature under aerobic atmosphere with gentle shaking (table S1). The yeasts were grown in malt extract-yeast extract (YM) medium and incubated at $30^{\circ} \mathrm{C}$. PA and LP were grown in MRS medium and incubated at $37^{\circ} \mathrm{C}$, whereas BP was grown in Bacillus medium supplemented with $\mathrm{NaCl}$ and incubated at $30^{\circ} \mathrm{C}$. The total cell count was determined by measuring the optical density at $600 \mathrm{~nm}$. The sucrose syrup $(1: 1 ; \mathrm{w} / \mathrm{v})$ was supplemented with probiotic candidates to achieve a final concentration of $10^{4} \mathrm{CFU} / \mathrm{mL}$. Strain survival in the sucrose syrup has been checked by inoculating $10^{4} \mathrm{CFU} / \mathrm{mL}$ of each strain in the syrup, incubated up to $48 \mathrm{~h}$ at $33^{\circ} \mathrm{C}$ (the temperature used for honeybee rearing) and enumerated on specific agar media. Doses of probiotic candidates used in these experiments were based on previous reports (Audisio and Benítez-Ahrendts, 2011; Ptaszyńska et al., 2016). The feeders were changed every $48 \mathrm{~h}$ and the amount of probiotics daily consumed per honeybee was estimated from the sucrose consumption.

\section{Sampling, gut dissection and storage conditions}


DNA and RNA extractions were performed at DO from the intestinal tracts of six introduced foragers and six emerging bees and also from the $N$. ceranae spore solution used for the infection. At day 18, a random sampling of six bees per cage was done. Before extraction, each bee was dissected with sterilized tweezers on ice. Each sample from the intestinal tracts (from the anterior intestine to the rectum) was divided into two pools of three guts which were extracted in tubes containing $600 \mu \mathrm{L}$ RLT buffer (AllPrep DNA/RNA Mini kit, Qiagen, Courtaboeuf, France) and 1\% of 2-mercaptoethanol and then were frozen in liquid nitrogen.

\section{DNA/RNA co-extraction}

Upon thawing, $60 \mathrm{mg}$ of glass beads $(0.1 \mathrm{~mm}$, SIGMA, St. Quentin Fallavier, France) previously treated with diethylpyrocarbonate were added and mechanical grinding using three cycles of $20 \mathrm{~s}$ was performed (Bead-beater MM30, Retsch, Haan, Germany). After centrifuging $1 \mathrm{~min}$ at $600 \times \mathrm{g}$ at $4^{\circ} \mathrm{C}$, supernatants were kept in DNase/RNase free tubes and subjected to three cycles of freeze-thaw (liquid nitrogen $/ 65^{\circ} \mathrm{C}$ ). Samples were then centrifuged at $8,000 \times \mathrm{g}$ for $10 \mathrm{~min}$ at $4^{\circ} \mathrm{C}$ and the supernatant was transferred in DNA column and centrifuged $1 \mathrm{~min}$ at $8,000 \times \mathrm{g}$. The simultaneous purification of DNA and RNA was done according to the manufacturer (AllPrep DNA/RNA Mini kit, Qiagen). The two pools of RNA for each cage were collected in the same final tube, received two treatments with DNase (RNase-Free DNase Set, Qiagen) and were stored at $-80^{\circ} \mathrm{C}$. Purified DNA and RNA were quantified by NanoDrop ${ }^{\mathrm{TM}} 2000$ spectrophotometer (Thermo Fisher Scientific, Illkirch, France) and the RNA concentration was measured using the Agilent 2200 Tape Station and the RNA ScreenTape kit (Agilent Technologies, Les Ulis, France).

\section{16S rRNA gene amplification}


The reverse transcription reaction was performed with random primers using the SuperScript III Reverse Transcriptase kit (Invitrogen ${ }^{\mathrm{TM}}$ ). Both DNA and CDNA coding for $16 \mathrm{~S}$ rRNA were amplified with the universal primer 515F (5'-GTGYCAGCMGCCGCGGTA-3') and bacteria/archaea specific primer 909R (5'-CCCCGYCAATTCMTTTRAGT-3') targeting the V3/V4 region. Primers were modified by adding specific barcodes ( 8 nucleotides) to assign the amplicons to each condition. PCR was performed using a high-fidelity polymerase (Platinium $^{\mathrm{TM}}$ Taq DNA polymerase high-fidelity, Invitrogen ${ }^{\mathrm{TM}}$ ), and the program was done as follows: $94^{\circ} \mathrm{C}$ for $3 \mathrm{~min}$, and $30 \mathrm{cycles}$ of $94^{\circ} \mathrm{C}$ for $30 \mathrm{~s}$, annealing at $59^{\circ} \mathrm{C}$ for $30 \mathrm{~s}$, elongation at $68^{\circ} \mathrm{C}$ for $30 \mathrm{~s}$ and a final elongation at $68^{\circ} \mathrm{C}$ for $7 \mathrm{~min}$. Reactions were realized in the thermocycler Proflex (Applied Biosystems). Electrophoresis on a 2\% (p/v) agarose gel was performed to check the size of PCR products. Then the amplicons were purified and concentrated using the Qiagen Gel extraction kits (Qiagen) and quantified using The Agilent 2200 Tape Station system and the D1000 ScreenTape kit (Agilent Technologies). An amplicon equimolar mixture $(20 \mathrm{ng} / \mu \mathrm{L})$ was constructed in a concentration for Illumina MiSeq Sequencing Technology (Run type: Paired end-Read length: 2 × 300 bp) by GATC Biotech.

\section{Taxonomic affiliations}

Sequences were analysed using vsearch tool (https://github.com/torognes/vsearch). The MiSEQ data were assembled, sequences having ambiguous bases " $N$ " were removed as well as if they had a mismatch in the forward and reverse primers or a length shorter than 200 bp. The putative chimaeras were removed using vsearch (denovo command). The bacterial reads were clustered into operational taxonomic units (OTUs) with $97 \%$ similarity using vsearch (Kim et al., 2011). The cleaned reads were clustered to identify a representative sequence for each OTU and were inserted into phylogenetic trees for taxonomic annotation. They were then affiliated by similarity and phylogeny with reference sequences extracted 
from the SSURef SILVA database (Pruesse et al., 2007). These sequences were extracted according to the criteria: (i) length $>1,200 \mathrm{bp}$, (ii) quality score $>75 \%$ and (iii) pintail value $>$ 50. Closest OTUs with reference sequences according to similarity approach (vsearch tool), were used to build trees with FastTree (Price et al., 2010). Taxonomic assignment was performed according to the Last Common Ancestor (LCA) affiliation using the pipeline PANAM (Phylogenetic Analysis of Next-generation AMplicons https://github.com/panammeb/) and is described in details in Taib et al. (Taib et al., 2013). To limit bias linked to differences in the number of sequences between samples, relative abundance was calculated for a semi-quantitative approach and sequences $<1 \%$ were removed from the analysis.

\section{9. $q P C R$}

Quantitative PCR experiments were carried out in a thermocycler Realplex2 (Eppendorf) to analyze the fold-change of five genes (table S2). QPCR reactions were performed in $20 \mu \mathrm{L}$ using $10 \mu$ l Absolute Blue qPCR SYBER GreenMix (Thermo Scientific), 10 pmol of each primer and $10 \mathrm{ng}$ cDNA on 96-well plates (Eurogentec RT-PL96-MQ). Amplification was conducted under the following protocol: $94^{\circ} \mathrm{C}$ for $10 \mathrm{~min}, 10$ cycles of $94^{\circ} \mathrm{C}$ for $40 \mathrm{~s}, 52^{\circ} \mathrm{C}$ for $40 \mathrm{~s}, 72^{\circ} \mathrm{C}$ for $30 \mathrm{~s}$, followed by one cycle of $95^{\circ} \mathrm{C}$ for $5 \mathrm{~s}$ and $65^{\circ} \mathrm{C}$ for $1 \mathrm{~min}$, then $40^{\circ} \mathrm{C}$ for $10 \mathrm{~s}$. QPCR data were expressed as the threshold cycle $(\mathrm{Ct})$ values normalized to RpS5a and calculated using the 2- $\Delta \Delta \mathrm{Ct}$ method following standard protocols (Schmittgen and Livak, 2008).

\section{Statistics}

Statistical analyses were performed using the statistical software R 3.2.5 (https://cran.rproject.org/). Survival analysis was performed using the Cox regression (proportional hazard model). For all statistical comparisons across different treatments, normality (Shapiro-Wilk) and the homogeneity of variances (Bartlett test) were verified. To determine whether the 
composition and structure of midgut bacterial communities differed significantly among treatments, statistical comparisons were made across the different conditions with KruskalWallis test followed by Dunn's test and the Benjamini-Hochberg correction. Correlation analyses between bacterial or yeast genera and the mortality were performed using nonparametric Spearman's rank tests. Different estimators were used to infer the taxa richness of the bacterial communities: the number of observed species (sequencing depth) and Shannon diversity indexes and ANOVA 1 was performed followed by two-tailed Student's t-test.

\section{Results}

\section{Experiment 1: Selection of probiotic candidates.}

The first experiment was conducted with eight experimental groups corresponding to uninfected or infected and probiotic-treated honeybees. Strain survival in the sucrose syrup was considered as satisfactory for S. cerevisiae (SC), S. boulardii (SB), P. acidilactici (PA) and B. pumilus (BP) for which either growth (for SC and SB) or a maximum reduction of $0.5 \log _{10}$ CFU (for PA and BP) was observed after $48 \mathrm{~h}$ at $33^{\circ} \mathrm{C}$. A lower survival was measured for the L. plantarum (LP) strain with a reduction by $1.0 \log 10$ CFU (data not shown).

The cumulative microbial strain consumption was the same in all treatments with an average of $2.10^{3} \mathrm{CFU} /$ bee. No significant difference in sucrose consumption was observed between treatments (data not shown). $N$. ceranae infection led to a significant decrease in honeybee survival as it decreased until $20.9 \%$ for the infected group (Inf.1) whereas the control group (Ctrl.1) one reached to $84.8 \%(p<0.001)$ (figure S1). Infected honeybees treated with LP, SC or BP had a significant higher survival rate $(44.6 \%, 48.6 \%$ and $66.6 \%$ of surviving bees at day 20 , respectively) than the infected group, but their survival rates remained lower than the control group ( $84.8 \%$ of surviving bees). More interestingly, both 
PA and SB induced a high increase of the honeybee survival compared with the infected group (2.3-fold, $p<0.001$ and 2.2 -fold, $p<0.001$ respectively for $\mathrm{PA}$ and SB) and showed no significant difference with the control group. Their effects on survival were similar to that measured in the fumagillin-treated group which was used as a positive control against $N$. ceranae infection. According to these results, PA was selected as the probiotic strain of interest for the second experiment (Exp.2).

2. Effects of the probiotic PA on bee mortality, sucrose consumption and $\mathbf{N}$. ceranae spore load.

In the second experiment (Exp.2), the probiotic PA was tested on honeybees infected by $N$. ceranae or co-exposed to two pesticides: the insecticide thiamethoxam and the fungicide boscalid. The sucrose consumption was significantly higher in the infected group compared with the control group (2-fold, $p=0.021$ ) (figure 2 ). Infected honeybees treated with PA (InfPA.2) also had a higher consumption than the control group (Ctrl.2, 1.3-fold) but this increase was significantly less important compared with the infected group (Inf.2, 1.4-fold). No difference was observed on sucrose consumption in the groups of bees exposed to pesticides (ThBo.2, ThBoPA.2) and the amount of consumed pesticides was on average of $2.94 \mathrm{ng} / \mathrm{bee} /$ day for thiamethoxam and $196.5 \mathrm{ng} / \mathrm{bee} /$ day for boscalid. The consumption of PA was on average of $2.5 \times 10^{2} \mathrm{CFU} / 24 \mathrm{~h}$ per bee.

The survival of honeybees only treated with PA (PA.2) showed no significant difference with the control group (Ctrl.2, $p=0.870$ ) suggesting that PA did not exhibit any toxic effect (figure 3). The co-exposure of honeybees to the insecticide thiamethoxam and to the fungicide boscalid (ThBo.2) led to a significant decrease in survival compared with the control group (Ctrl.2) with respectively $59.0 \%$ and $88.9 \%$ of survival rate $(p<0.001)$. The treatment with PA fully restored the survival of honeybees exposed to pesticides $(87.3 \%$ of survival bees, 
p $<0.001$ for comparison between ThBo.2 and ThBoPA.2); no significant difference was observed between ThBoPA.2 and Ctrl.2 group. Infection by N. ceranae induced a decrease of 3.0-fold the rate of honeybee survival in the Inf.2 group compared with the control group $(p<0.001)$. The survival rate of the infected group treated with PA (InfPA.2) significantly increased compared with the Inf.2 group $(1.7$-fold, $p<0.001)$ although the survival remained lower than the Ctrl.2 group $(1.3$-fold, $\mathrm{p}<0.001)$. Furthermore, treatment with PA induced a significant decrease of the spore load compared with the Inf.2 group (5.4-fold, $p<0.001$ ) (figure 4).

\section{Response of bacterial microbiota to different stressors and probiotic treatment}

In order to detect effects of the different treatments on the midgut bacterial community, a sampling was performed at day 16 (corresponding to significant effects of infection and intoxication) and RNA was extracted from the midguts to perform a metagenomic analysis. After filtering, the average number of sequences was 2,513,863 from 27 samples (9 conditions $\times 3$ replicates), each sample comprising a pool of RNA corresponding to six honeybees. In all treatments, dominant bacterial taxa were composed of four classes (Bacilli, Gammaproteobacteria, Alphaproteobacteria and Betaproteobacteria), five orders (Lactobacillales, Rhizobiales, Rhodospirillales, Neisseriales and Orbales) and four genera (Lactobacillus, Bartonella, Orbus and Gilliamella, data not shown) (figure 5). Honeybee gut microbiota were similar in control and forager groups suggesting that the implantation of the gut microbiota in experimental conditions was quite successful (figure S2). The infection by $N$. ceranae and the co-exposure to pesticides revealed no significant difference on the gut microbiota composition compared with the control group. The study of the composition of bacterial community structure was also performed by analyzing the alpha diversity (through the Shannon index) and the beta diversity (Factorial Analysis Correspondence) but no 
significant difference was observed between the different treatments and the control (figure

6). It is important to note that $20-40 \%$ of the sequences could not be affiliated to any genus, as we used the LCA (lowest common ancestor) assignment method that demonstrated to be more accurate (Taib et al., 2013) but enabling a lower assignation in our case.

\section{Effects of treatments on targeted host gene expression}

The mRNA expression of five genes involved in different functions was followed by quantitative PCR (figure 7). Downregulations were observed in the expression of two genes involved in the detoxification and antioxidant systems : the gene coding for the catalase (Gene ID 443552) and for the glutathione peroxidase-like 2 (Gene ID726269). The expression level of these two genes was significantly downregulated in infected (Inf.2) and cointoxicated (ThBo.2 and ThBoPA.2) honeybees, except for infected honeybees treated with the probiotic PA (InfPA.2) which had a similar expression level with the control group (Ctrl.2). The transcript levels of two genes involved in immunity were also reduced in the gut in response to the infection by $N$. ceranae. The gene coding for the defensin (Gene ID406143) was significantly downregulated in Inf.2, ThBo.2 and ThBoPA.2 groups whereas its expression was significantly upregulated in infected honeybees treated with PA (InfPA.2). The expression level of the gene coding for the serine protease 40 (Gene ID409626) was significantly lower in infected honeybees (Inf.2) than in the control group (Ctrl.2) while no difference was observed between InfPA.2 and Ctrl.2 groups. On the contrary, honeybees coexposed to thiamethoxam and boscalid (ThBo.2) had a significant higher expression level of the serine protease 40 encoding gene than Ctrl.2 but no significant difference was observed between ThBoPA.2 and Ctrl.2. Finally, the vitellogenin encoding gene was significantly downregulated in Inf.2 and upregulated in ThBo.2 whereas no significant difference was observed in both PA-treated groups (InfPA.2 and ThBoPA.2). 


\section{Discussion}

Since the antibiotic fumagillin has been withdrawn from the European market, there is no other available treatment to fight the parasite $N$. ceranae. Given the importance of the gut microbiota, increasingly number of studies investigated on the efficiency of probiotic treatments (Audisio et al., 2015; Baffoni et al., 2016; Corby-Harris et al., 2014; Gaggìa et al., 2018; Ptaszyńska et al., 2016). In the present work, a PA strain appeared to be the most efficient probiotic against $N$. ceranae (Exp.1). The treatment with PA has not disturbed the midgut microbiota community (neither abundance or diversity). Furthermore, PA was not identified in the metagenomic analysis suggesting that it was not established in the gut microbiota or only as a minor component. This probiotic treatment has completely restored the survival rates of infected honeybees in Exp.1 suggesting that PA treatment efficiency is enhanced when it is administered before the infection. The survival rate improvement by PA has already been shown in both curative and prophylactic administrations with a survival probability enhance of $20-30 \%$ in honeybees treated with a commercial product containing the same strain (El Khoury et al., 2018). Similar effects were highlighted with the prophylactic administration of Biogen- $\mathrm{N}$, a probiotic formulation containing PA among other strains (Kaznowski et al., 2005) and in other species like piglets (Di Giancamillo et al., 2008; Dowarah et al., 2018), red tilapia (Ferguson et al., 2010), rainbow trout (Merrifield et al., 2010) or chickens (Jazi et al., 2018).

As previously reported, $N$. ceranae induced an increase of sucrose consumption arguing for an energetic stress (Mayack and Naug, 2009; Vidau et al., 2011). This increase was counterbalanced when honeybees were treated with PA and we can hypothesize that this could be due to a greater digestibility as it was demonstrated in chickens infected by the pathogenic bacteria Salmonella Typhimurium (Jazi et al., 2018) or in piglets (Dowarah et al., 
2018). PA has also shown an efficiency to reduce the oxidative stress in different species including Litopenaeus stylirostris infected by Vibrio nigripulchritudo (Castex et al., 2010) and Oncorhynchus mykiss infected by Streptococcus (Hoseinifar et al., 2017). In our study, the expression of genes encoding catalase and glutathione peroxidase involved in antioxidant reaction and xenobiotic detoxification was decreased in infected bees suggesting a disruption of the oxidative balance as previously reported by Aufauvre et al. (Aufauvre et al., 2014) and Paris et al. (Paris et al., 2017). The oxidative balance is essential for the honeybee health since reactive oxygen species (ROS) could be both beneficial (immune defence, signal transduction, cell cycle regulation) and dangerous (DNA, lipid or protein damages) for the honeybees (Chiu and Dawes, 2012; Finkel, 2011). The treatment with PA restored their expression levels, suggesting that this probiotic strain may be involved in a mechanism, that needs to be deciphered, which would contribute to reduce the oxidative stress deleterious to honeybees. Other honeybee functions were altered by $N$. ceranae infection, including the downregulation of the genes coding for serine protease 40 and defensin, which is in line with previously reported data (Antunez et al., 2009; Aufauvre et al., 2014; Chaimanee et al., 2013) but in discordance with another study (Li et al., 2017). This discrepancy may be due to differences in honeybee susceptibility to N. ceranae as previously described (Kurze et al., 2015). Indeed, the honeybees analysed in the work of Li et al. (Li et al., 2017), contrary to our study, could therefore correspond to Nosema-tolerant honeybees. The analysed genes are linked to the immune response since the serine protease 40 is involved in the regulatory cascade reaction which activates the prophenoloxidase and Toll pathways leading, for the latter, to the production of antimicrobial peptides like defensin. The expression level of the serine protease 40 was restored and gene coding for the defensin was overexpressed when honeybees were fed with PA. This result suggests that PA treatment may have a protective 
action against $N$. ceranae infection. In the same vein, the treatment with PA induced a 5-fold reduction of the $N$. ceranae spore load. Taken together, these results suggest that the probiotic PA might be used to prevent infection by the parasite N. ceranae.

Honeybees are also chronically exposed to multiple abiotic stressors like pesticides. Indeed, a multitude of pesticides were detected in honeybees and hive matrices including pollen, honey and wax (Jabot et al., 2016; Kasiotis et al., 2014; Lambert et al., 2013; Mullin et al., 2010; Simon-Delso et al., 2015) and could affect them at both lethal and sub-lethal levels. In this study, we have observed the effects of the chronical co-exposure to an insecticide (thiamethoxam) and a fungicide (boscalid) at low doses. The association of these two pesticides appeared to be deleterious for honeybees with a significant increase of mortality. Interestingly, the treatment with the PA strain completely restored honeybee survival rate. The mechanism through which this treatment acts on pesticide intoxication is unknown, but we showed that the PA treatment restored the expression of two genes which were altered by the pesticide co-exposure, those coding for serine protease 40 and vitellogenin. Previous studies have shown that induction of vitellogenin transcript could be used as a biomarker for neonicotinoid exposure (Christen et al., 2017). Changes in expression levels of these two genes showed the beneficial action of PA treatment. Furthermore, Lactobacilli have shown potentials to sequester and degrade environmental toxins. They could sequester, but not metabolize, organophosphate pesticides (parathion and chlorpyrifos) and this sequestration was associated with decreased intestinal absorption and insect toxicity in appropriate models (Trinder et al., 2016). This could also be the case for PA in our experiments and this potential ability deserves to be studied more in detail.

In our opinion, the use of the PA strain may represent a prophylactic and natural tool to protect honeybees from both $N$. ceranae infection and pesticide exposure. However, studies 
in natural conditions need to be undertaken to assess the efficiency of PA at the colony level in different landscapes against nosemosis and intoxications.

\section{Acknowledgements}

This work was funded by the ELISA grant from the Rovaltain Scientific Cooperation foundation (http://www.fcsrovaltain.org) and from the French National Research Agency (ANR, grant number ANR-12-BSV3-0020). E.P. was supported by a grant from the Rovaltain Scientific Cooperation foundation.

\section{References}

Alaux, C., Brunet, J.-L., Dussaubat, C., Mondet, F., Tchamitchan, S., Cousin, M., Brillard, J., Baldy, A., Belzunces, L.P., Le Conte, Y., 2010. Interactions between Nosema microspores and a neonicotinoid weaken honeybees ( Apis mellifera ). Environ. Microbiol. 12, 774782. https://doi.org/10.1111/j.1462-2920.2009.02123.x

Antunez, K., Martin-Hernandez, R., Prieto, L., Meana, A., Zunino, P., Higes, M., 2009. Immune suppression in the honey bee (Apis mellifera) following infection by Nosema ceranae (Microsporidia). Env. Microbiol 11, 2284-2290. https://doi.org/10.1111/j.14622920.2009.01953.x

Audisio, M., Benítez-Ahrendts, M., 2011. Lactobacillus johnsonii CRL1647, isolated from Apis mellifera L. bee-gut, exhibited a beneficial effect on honeybee colonies. Benef. Microbes 2, 29-34. https://doi.org/10.3920/BM2010.0024

Audisio, M.C., Sabaté, D.C., Benítez-Ahrendts, M.R., 2015. Effect of Lactobacillus johnsonii CRL1647 on different parameters of honeybee colonies and bacterial populations of the bee gut. Benef. Microbes 6, 687-695. https://doi.org/10.3920/BM2014.0155 
Aufauvre, J., Biron, D.G., Vidau, C., Fontbonne, R., Roudel, M., Diogon, M., Viguès, B., Belzunces, L.P., Delbac, F., Blot, N., 2012. Parasite-insecticide interactions: a case study of Nosema ceranae and fipronil synergy on honeybee. Sci. Rep. 2, 326. https://doi.org/10.1038/srep00326

Aufauvre, J., Misme-Aucouturier, B., Viguès, B., Texier, C., Delbac, F., Blot, N., 2014.

Transcriptome analyses of the honeybee response to Nosema ceranae and insecticides.

PLoS One 9, e91686. https://doi.org/10.1371/journal.pone.0091686

Avenot, H.F., Michailides, T.J., 2007. Resistance to Boscalid Fungicide in Alternaria alternata Isolates from Pistachio in California. Plant Dis. 91, 1345-1350.

https://doi.org/10.1094/PDIS-91-10-1345

Baffoni, L., Gaggia, F., Alberoni, D., Cabbri, R., Nanetti, A., Biavati, B., Di Gioia, D., 2016. Effect of dietary supplementation of Bifidobacterium and Lactobacillus strains in Apis mellifera L. against Nosema ceranae. Benef. Microbes 7, 45-51. https://doi.org/10.3920/BM2015.0085

Casida, J.E., Durkin, K.A., 2013. Neuroactive Insecticides: Targets, Selectivity, Resistance, and Secondary Effects. Annu. Rev. Entomol. 58, 99-117. https://doi.org/10.1146/annurevento-120811-153645

Castex, M., Lemaire, P., Wabete, N., Chim, L., 2010. Effect of probiotic Pediococcus acidilactici on antioxidant defences and oxidative stress of Litopenaeus stylirostris under Vibrio nigripulchritudo challenge. Fish Shellfish Immunol. 28, 622-631. https://doi.org/10.1016/j.fsi.2009.12.024

Chaimanee, V., Pettis, J.S., Chen, Y., Evans, J.D., Khongphinitbunjong, K., Chantawannakul, P., 2013. Susceptibility of four different honey bee species to Nosema ceranae. Vet. Parasitol. 193, 260-265. https://doi.org/10.1016/j.vetpar.2012.12.004 
Chiu, J., Dawes, I.W., 2012. Redox control of cell proliferation. Trends Cell Biol. 22, 592-601. https://doi.org/10.1016/j.tcb.2012.08.002

Christen, V., Bachofer, S., Fent, K., 2017. Binary mixtures of neonicotinoids show different transcriptional changes than single neonicotinoids in honeybees (Apis mellifera). Environ. Pollut. 220, 1264-1270. https://doi.org/10.1016/j.envpol.2016.10.105

Corby-Harris, V., Maes, P., Anderson, K.E., 2014. The Bacterial Communities Associated with Honey Bee (Apis mellifera) Foragers. PLoS One 9, e95056. https://doi.org/10.1371/journal.pone.0095056

Cox-Foster, D.L., Conlan, S., Holmes, E.C., Palacios, G., Evans, J.D., Moran, N.A., Quan, P.-L., Briese, T., Hornig, M., Geiser, D.M., Martinson, V., VanEngelsdorp, D., Kalkstein, A.L., Drysdale, A., Hui, J., Zhai, J., Cui, L., Hutchison, S.K., Simons, J.F., Egholm, M., Pettis, J.S., Lipkin, W.I., 2007. A Metagenomic Survey of Microbes in Honey Bee Colony Collapse Disorder. Science (80-. ). 318, 283-287. https://doi.org/10.1126/science.1146498 Crotti, E., Balloi, A., Hamdi, C., Sansonno, L., Marzorati, M., Gonella, E., Favia, G., Cherif, A., Bandi, C., Alma, A., Daffonchio, D., 2012. Microbial symbionts: a resource for the management of insect-related problems. Microb. Biotechnol. 5, 307-317. https://doi.org/10.1111/j.1751-7915.2011.00312.x

Degrandi-Hoffman, G., Chen, Y., Watkins Dejong, E., Chambers, M.L., Hidalgo, G., 2015. Effects of Oral Exposure to Fungicides on Honey Bee Nutrition and Virus Levels. J. Econ. Entomol. 108, 2518-2528. https://doi.org/10.1093/jee/tov251

Di Giancamillo, A., Vitari, F., Savoini, G., Bontempo, V., Bersani, C., Dell'Orto, V., Domeneghini, C., 2008. Effects of orally administered probiotic Pediococcus acidilactici on the small and large intestine of weaning piglets. A qualitative and quantitative micro-anatomical study. Histol. Histopathol. 23, 651-664. https://doi.org/10.14670/HH- 
23.651

Dowarah, R., Verma, A.K., Agarwal, N., Singh, P., 2018. Efficacy of species-specific probiotic Pediococcus acidilactici FT28 on blood biochemical profile, carcass traits and physicochemical properties of meat in fattening pigs. Res. Vet. Sci. 117, 60-64. https://doi.org/10.1016/j.rvsc.2017.11.011

Dussaubat, C., Brunet, J.-L., Higes, M., Colbourne, J.K., Lopez, J., Choi, J.-H., MartínHernández, R., Botías, C., Cousin, M., McDonnell, C., Bonnet, M., Belzunces, L.P., Moritz, R.F.A., Le Conte, Y., Alaux, C., 2012. Gut Pathology and Responses to the Microsporidium Nosema ceranae in the Honey Bee Apis mellifera. PLoS One 7, e37017. https://doi.org/10.1371/journal.pone.0037017

Dussaubat, C., Maisonnasse, A., Alaux, C., Tchamitchan, S., Brunet, J.-L., Plettner, E., Belzunces, L.P., Le Conte, Y., 2010. Nosema spp. Infection Alters Pheromone Production in Honey Bees (Apis mellifera). J. Chem. Ecol. 36, 522-525. https://doi.org/10.1007/s10886-010-9786-2

Dussaubat, C., Maisonnasse, A., Crauser, D., Tchamitchian, S., Bonnet, M., Cousin, M., Kretzschmar, A., Brunet, J.-L., Le Conte, Y., 2016. Combined neonicotinoid pesticide and parasite stress alter honeybee queens' physiology and survival. Sci. Rep. 6, 31430. https://doi.org/10.1038/srep31430

El Khoury, S., Rousseau, A., Lecoeur, A., Cheaib, B., Bouslama, S., Mercier, P.-L., Demey, V., Castex, M., Giovenazzo, P., Derome, N., 2018. Deleterious Interaction Between Honeybees (Apis mellifera) and its Microsporidian Intracellular Parasite Nosema ceranae Was Mitigated by Administrating Either Endogenous or Allochthonous Gut Microbiota Strains. Front. Ecol. Evol. 6. https://doi.org/10.3389/fevo.2018.00058 Engel, P., Martinson, V.G., Moran, N.A., 2012. Functional diversity within the simple gut 
microbiota of the honey bee. Proc. Natl. Acad. Sci. 109, 11002-11007.

https://doi.org/10.1073/pnas.1202970109

Ferguson, R.M.W., Merrifield, D.L., Harper, G.M., Rawling, M.D., Mustafa, S., Picchietti, S., Balcázar, J.L., Davies, S.J., 2010. The effect of Pediococcus acidilactici on the gut microbiota and immune status of on-growing red tilapia (Oreochromis niloticus). J. Appl. Microbiol. 109, 851-862. https://doi.org/10.1111/j.1365-2672.2010.04713.x

Finkel, T., 2011. Signal transduction by reactive oxygen species. J. Cell Biol. https://doi.org/10.1083/jcb.201102095

Gaggìa, F., Baffoni, L., Alberoni, D., 2018. Probiotics for Honeybees' Health, in: Probiotics and Prebiotics in Animal Health and Food Safety. Springer International Publishing, Cham, pp. 219-245. https://doi.org/10.1007/978-3-319-71950-4_9

García-Palencia, P., Martín-Hernández, R., González-Porto, A.-V., Marin, P., Meana, A., Higes, M., 2010. Natural infection by Nosema ceranae causes similar lesions as in experimentally infected caged-worker honey bees ( Apis mellifera ). J. Apic. Res. 49, 278-283. https://doi.org/10.3896/IBRA.1.49.3.08

Goblirsch, M., Huang, Z.Y., Spivak, M., 2013. Physiological and Behavioral Changes in Honey Bees (Apis mellifera) Induced by Nosema ceranae Infection. PLoS One 8, e58165. https://doi.org/10.1371/journal.pone.0058165

Henry, M., Cerrutti, N., Aupinel, P., Decourtye, A., Gayrard, M., Odoux, J.-F., Pissard, A., Rüger, C., Bretagnolle, V., 2015. Reconciling laboratory and field assessments of neonicotinoid toxicity to honeybees. Proc. R. Soc. B Biol. Sci. 282, 20152110. https://doi.org/10.1098/rspb.2015.2110

Higes, M., Martín-Hernández, R., Botías, C., Bailón, E.G., González-Porto, A. V., Barrios, L., del Nozal, M.J., Bernal, J.L., Jiménez, J.J., Palencia, P.G., Meana, A., 2008. How natural 
infection by Nosema ceranae causes honeybee colony collapse. Environ. Microbiol. 10, 2659-2669. https://doi.org/10.1111/j.1462-2920.2008.01687.x

Hoseinifar, S.H., Mirvaghefi, A., Amoozegar, M.A., Merrifield, D.L., Ring $\varnothing$, E., 2017. In vitro selection of a synbiotic and in vivo evaluation on intestinal microbiota, performance and physiological response of rainbow trout ( Oncorhynchus mykiss) fingerlings. Aquac. Nutr. 23, 111-118. https://doi.org/10.1111/anu.12373

Jabot, C., Daniele, G., Giroud, B., Tchamitchian, S., Belzunces, L.P., Casabianca, H., Vulliet, E., 2016. Detection and quantification of boscalid and its metabolites in honeybees. Chemosphere 156, 245-251. https://doi.org/10.1016/j.chemosphere.2016.04.135

Jazi, V., Foroozandeh, A.D., Toghyani, M., Dastar, B., Rezaie Koochaksaraie, R., Toghyani, M., 2018. Effects of Pediococcus acidilactici, mannan-oligosaccharide, butyric acid and their combination on growth performance and intestinal health in young broiler chickens challenged with Salmonella Typhimurium. Poult. Sci. 97, 2034-2043. https://doi.org/10.3382/ps/pey035

Kasiotis, K.M., Anagnostopoulos, C., Anastasiadou, P., Machera, K., 2014. Pesticide residues in honeybees, honey and bee pollen by LC-MS/MS screening: reported death incidents in honeybees. Sci. Total Environ. 485-486, 633-642.

Kaznowski, A., Szymas, B., Jazdzinska, E., Kazimierczak, M., Paetz, H., Mokracka, J., 2005. The effects of probiotic supplementation on the content of intestinal microflora and chemical composition of worker honey bees ( Apis mellifera ). J. Apic. Res. 44, 10-14. https://doi.org/10.1080/00218839.2005.11101139

Kim, M., Morrison, M., Yu, Z., 2011. Evaluation of different partial 16S rRNA gene sequence regions for phylogenetic analysis of microbiomes. J. Microbiol. Methods 84, 81-87. https://doi.org/10.1016/j.mimet.2010.10.020 
Kurze, C., Le Conte, Y., Dussaubat, C., Erler, S., Kryger, P., Lewkowski, O., Müller, T., Widder, M., Moritz, R.F.A., 2015. Nosema tolerant honeybees (apis mellifera) escape parasitic manipulation of apoptosis. PLoS One. https://doi.org/10.1371/journal.pone.0140174

Lambert, O., Piroux, M., Puyo, S., Thorin, C., L’Hostis, M., Wiest, L., Buleté, A., Delbac, F., Pouliquen, H., 2013. Widespread Occurrence of Chemical Residues in Beehive Matrices from Apiaries Located in Different Landscapes of Western France. PLoS One 8, e67007. https://doi.org/10.1371/journal.pone.0067007

Leonhardt, S.D., Kaltenpoth, M., 2014. Microbial Communities of Three Sympatric Australian Stingless Bee Species. PLoS One 9, e105718.

https://doi.org/10.1371/journal.pone.0105718

Li, W., Evans, J.D., Li, J., Su, S., Hamilton, M., Chen, Y., 2017. Spore load and immune response of honey bees naturally infected by Nosema ceranae. Parasitol. Res. https://doi.org/10.1007/s00436-017-5630-8

Martín-Hernández, R., Meana, A., Prieto, L., Salvador, A.M., Garrido-Bailón, E., Higes, M., 2007. Outcome of colonization of Apis mellifera by Nosema ceranae. Appl. Environ. Microbiol. https://doi.org/10.1128/AEM.00270-07

Martinson, V.G., Moy, J., Moran, N.A., 2012. Establishment of Characteristic Gut Bacteria during Development of the Honeybee Worker. Appl. Environ. Microbiol. 78, 2830-2840. https://doi.org/10.1128/AEM.07810-11

Mayack, C., Naug, D., 2009. Energetic stress in the honeybee Apis mellifera from Nosema ceranae infection. J. Invertebr. Pathol. 100, 185-188. https://doi.org/10.1016/j.jip.2008.12.001

Merrifield, D.L., Bradley, G., Baker, R.T.M., Davies, S.J., 2010. Probiotic applications for rainbow trout (Oncorhynchus mykiss Walbaum) II. Effects on growth performance, feed 
utilization, intestinal microbiota and related health criteria postantibiotic treatment. Aquac. Nutr. 16, 496-503. https://doi.org/10.1111/j.1365-2095.2009.00688.x

Moran, N.A., Hansen, A.K., Powell, J.E., Sabree, Z.L., 2012. Distinctive Gut Microbiota of Honey Bees Assessed Using Deep Sampling from Individual Worker Bees. PLoS One 7, e36393. https://doi.org/10.1371/journal.pone.0036393

Mullin, C.A., Frazier, M., Frazier, J.L., Ashcraft, S., Simonds, R., VanEngelsdorp, D., Pettis, J.S., 2010. High Levels of Miticides and Agrochemicals in North American Apiaries: Implications for Honey Bee Health. PLoS One 5, e9754. https://doi.org/10.1371/journal.pone.0009754

Panek, J., Paris, L., Roriz, D., Mone, A., Dubuffet, A., Delbac, F., Diogon, M., El Alaoui, H., 2018. Impact of the microsporidian Nosema ceranae on the gut epithelium renewal of the honeybee, Apis mellifera. J. Invertebr. Pathol. 159, 121-128.

https://doi.org/10.1016/j.jip.2018.09.007

Paris, L., Roussel, M., Pereira, B., Delbac, F., Diogon, M., 2017. Disruption of oxidative balance in the gut of the western honeybee Apis mellifera exposed to the intracellular parasite Nosema ceranae and to the insecticide fipronil. Microb. Biotechnol. 10, 17021717. https://doi.org/10.1111/1751-7915.12772

Potts, S.G., Biesmeijer, J.C., Kremen, C., Neumann, P., Schweiger, O., Kunin, W.E., 2010. Global pollinator declines: trends, impacts and drivers. Trends Ecol. Evol. 25, 345-353. https://doi.org/10.1016/j.tree.2010.01.007

Powell, J.E., Martinson, V.G., Urban-Mead, K., Moran, N.A., 2014. Routes of Acquisition of the Gut Microbiota of the Honey Bee Apis mellifera. Appl. Environ. Microbiol. 80, 73787387. https://doi.org/10.1128/AEM.01861-14

Price, M.N., Dehal, P.S., Arkin, A.P., 2010. FastTree 2 - Approximately Maximum-Likelihood 
Trees for Large Alignments. PLoS One 5, e9490.

https://doi.org/10.1371/journal.pone.0009490

Pruesse, E., Quast, C., Knittel, K., Fuchs, B.M., Ludwig, W., Peplies, J., Glöckner, F.O., 2007.

SILVA: a comprehensive online resource for quality checked and aligned ribosomal RNA sequence data compatible with ARB. Nucleic Acids Res. 35, 7188-96.

https://doi.org/10.1093/nar/gkm864

Ptaszyńska, A.A., Borsuk, G., Zdybicka-Barabas, A., Cytryńska, M., Małek, W., 2016. Are commercial probiotics and prebiotics effective in the treatment and prevention of honeybee nosemosis C? Parasitol. Res. 115, 397-406. https://doi.org/10.1007/s00436015-4761-z

Roussel, M., Villay, A., Delbac, F., Michaud, P., Laroche, C., Roriz, D., El Alaoui, H., Diogon, M., 2015. Antimicrosporidian activity of sulphated polysaccharides from algae and their potential to control honeybee nosemosis. Carbohydr. Polym. 133, 213-220. https://doi.org/10.1016/j.carbpol.2015.07.022

Schmittgen, T.D., Livak, K.J., 2008. Analyzing real-time PCR data by the comparative CT method. Nat. Protoc. 3, 1101-1108. https://doi.org/10.1038/nprot.2008.73

Simon-Delso, N., Amaral-Rogers, V., Belzunces, L.P., Bonmatin, J.M., Chagnon, M., Downs, C., Furlan, L., Gibbons, D.W., Giorio, C., Girolami, V., Goulson, D., Kreutzweiser, D.P., Krupke, C.H., Liess, M., Long, E., Mcfield, M., Mineau, P., Mitchell, E.A., Morrissey, C.A., Noome, D.A., Pisa, L., Settele, J., Stark, J.D., Tapparo, A., Van Dyck, H., Van Praagh, J., Van Der Sluijs, J.P., Whitehorn, P.R., Wiemers, M., 2015. Systemic insecticides (Neonicotinoids and fipronil): Trends, uses, mode of action and metabolites. Environ. Sci. Pollut. Res. https://doi.org/10.1007/s11356-014-3470-y

Taib, N., Mangot, J.-F., Domaizon, I., Bronner, G., Debroas, D., 2013. Phylogenetic Affiliation 
of SSU rRNA Genes Generated by Massively Parallel Sequencing: New Insights into the Freshwater Protist Diversity. PLoS One 8, e58950.

https://doi.org/10.1371/journal.pone.0058950

Trinder, M., McDowell, T.W., Daisley, B.A., Ali, S.N., Leong, H.S., Sumarah, M.W., Reid, G., 2016. Probiotic Lactobacillus rhamnosus Reduces Organophosphate Pesticide Absorption and Toxicity to Drosophila melanogaster. Appl. Environ. Microbiol. 82, 6204-6213. https://doi.org/10.1128/AEM.01510-16

vanEngelsdorp, D., Meixner, M.D., 2010. A historical review of managed honey bee populations in Europe and the United States and the factors that may affect them. J. Invertebr. Pathol. 103, S80-S95. https://doi.org/10.1016/j.jip.2009.06.011

Vásquez, A., Forsgren, E., Fries, I., Paxton, R.J., Flaberg, E., Szekely, L., Olofsson, T.C., 2012. Symbionts as Major Modulators of Insect Health: Lactic Acid Bacteria and Honeybees. PLoS One 7, e33188. https://doi.org/10.1371/journal.pone.0033188

Vidau, C., Diogon, M., Aufauvre, J., Fontbonne, R., Viguès, B., Brunet, J.-L., Texier, C., Biron, D.G., Blot, N., El Alaoui, H., Belzunces, L.P., Delbac, F., 2011. Exposure to Sublethal Doses of Fipronil and Thiacloprid Highly Increases Mortality of Honeybees Previously Infected by Nosema ceranae. PLoS One 6, e21550. https://doi.org/10.1371/journal.pone.0021550

Zheng, H., Powell, J.E., Steele, M.I., Dietrich, C., Moran, N.A., 2017. Honeybee gut microbiota promotes host weight gain via bacterial metabolism and hormonal signaling. Proc. Natl. Acad. Sci. 114, 4775-4780. https://doi.org/10.1073/pnas.1701819114 
Figure 1. Experimental design. Emerging honeybees were collected from three different colonies and placed in cages in groups of 50 individuals. A. A preliminary experiment (Exp.1) was done to evaluate the effects of five different probiotics (PA, BP, SC, SB and LP) on bee mortality and sucrose consumption. Probiotics were administered two days before the infection by $N$. ceranae to investigate preventive effects. Fumagillin treatment was also given to infected honeybees as a positive control against $N$. ceranae. B. During the second experiment (Exp.2), the probiotic Pediococcus acidilactici (PA) was given to honeybees two days after infection by $N$. ceranae or exposure to pesticides (thiamethoxam + boscalid). Effects of probiotics on bee mortality, sucrose consumption and spore load were monitored, and sampling of individuals at day 16 was designed to metagenomics analysis of the gut microbiota. SC: Saccharomyces cerevisiae, SB: Saccharomyces boulardii, PA: Pediococcus acidilactici, BP: Bacillus pumilus, LP: Lactobacillus plantarum.

Figure 2: Sucrose consumption by infected or pesticide-exposed honeybees treated with the probiotic strain Pediococcus acidilactici (PA). The sucrose consumption was daily monitored during the experiment (g/bee/day \pm standard deviation $\mathrm{sd}$ ): uninfected and untreated (Ctrl.2), infected (Inf.2), infected and treated with PA (InfPA.2), intoxicated with both thiamethoxam and boscalid (ThBo.2) or intoxicated with pesticides and treated with PA (ThBoPA.2).

Figure 3. Pediococcus acidilactici (PA) effect on the survival of honeybees infected by $N$. ceranae or co-exposed to pesticides. This graph represents the cumulative proportion of surviving honeybees: untreated and uninfected (Ctrl.2), treated with PA (PA.2), infected (Inf.2), infected and treated with PA (InfPA.2), co-exposed to pesticides (ThBo.2) and co- 
exposed to pesticides and treated with PA (ThBoPA.2). Data were analysed from 150 honeybees per condition among Kaplan-Meier method.

Figure 4. Spore loads in honeybees infected by $\mathbf{N}$. ceranae and treated or not with Pediococcus acidilactici (PA). At the end of the experiment (d22), the spore production was evaluated from ten abdomens of honeybees per cage. The data show the mean number of spores per honeybee abdomen \pm standard deviation (sd) for each condition: infected and treated or not with PA (InfPA.2). Asterix indicate significant differences ( $\alpha=5 \%$ ).

Figure 5. Cumulative relative abundances of bacterial classes (A) or orders (B) from honeybee gut microbiota. The relative abundances of bacterial cDNA sequences from the 6 experimental groups are shown at two taxonomic levels: class and order.

Figure 6. Diversity analysis of the midgut microbiota of infected- or pesticide exposedhoneybees treated or not with Pediococcus acidilactici (PA). Diversity of honeybees untreated and uninfected (Ctrl.2), co-intoxicated with pesticides (ThBo.2), infected (Inf.2), treated with PA (PA.2), infected and treated with PA (InfPA.2) or co-intoxicated with pesticides and treated with PA (ThBoPA.2). A. The Factorial Correspondence Analysis (FCA) is an indicator of $\beta$-diversity and no significant difference was observed between the different treatments. B. On the same way, no significant difference was observed between the $\alpha-$ diversity of the different treatments.

Figure 7. Expression levels of honeybee genes in response to different treatments at day 16. This graph represents the mean of the log fold change of genes involved in the detoxification system (Catalase and Glutathione peroxidase-like 2) and genes involved in immunity (vitellogenin, serine protease 40 and defensin): intoxicated by pesticides (ThBo.2), 
infected by $N$. ceranae (Inf.2), intoxicated and treated with PA (ThBoPA.2), infected and treated with PA (InfPA.2). Asterix indicate significant differences ( $\alpha=5 \%)$.

Highlights

- The honeybee physiology is disturbed by Nosema ceranae and pesticides.

- A Pediococcus strain can rescue honeybees from $N$. ceranae- and pesticide adverse effects.

- The Pediococcus strain can act by stimulating the honeybee immune and detoxication systems. Graphical abstract 
A Daily monitoring of mortality and sucrose consumption

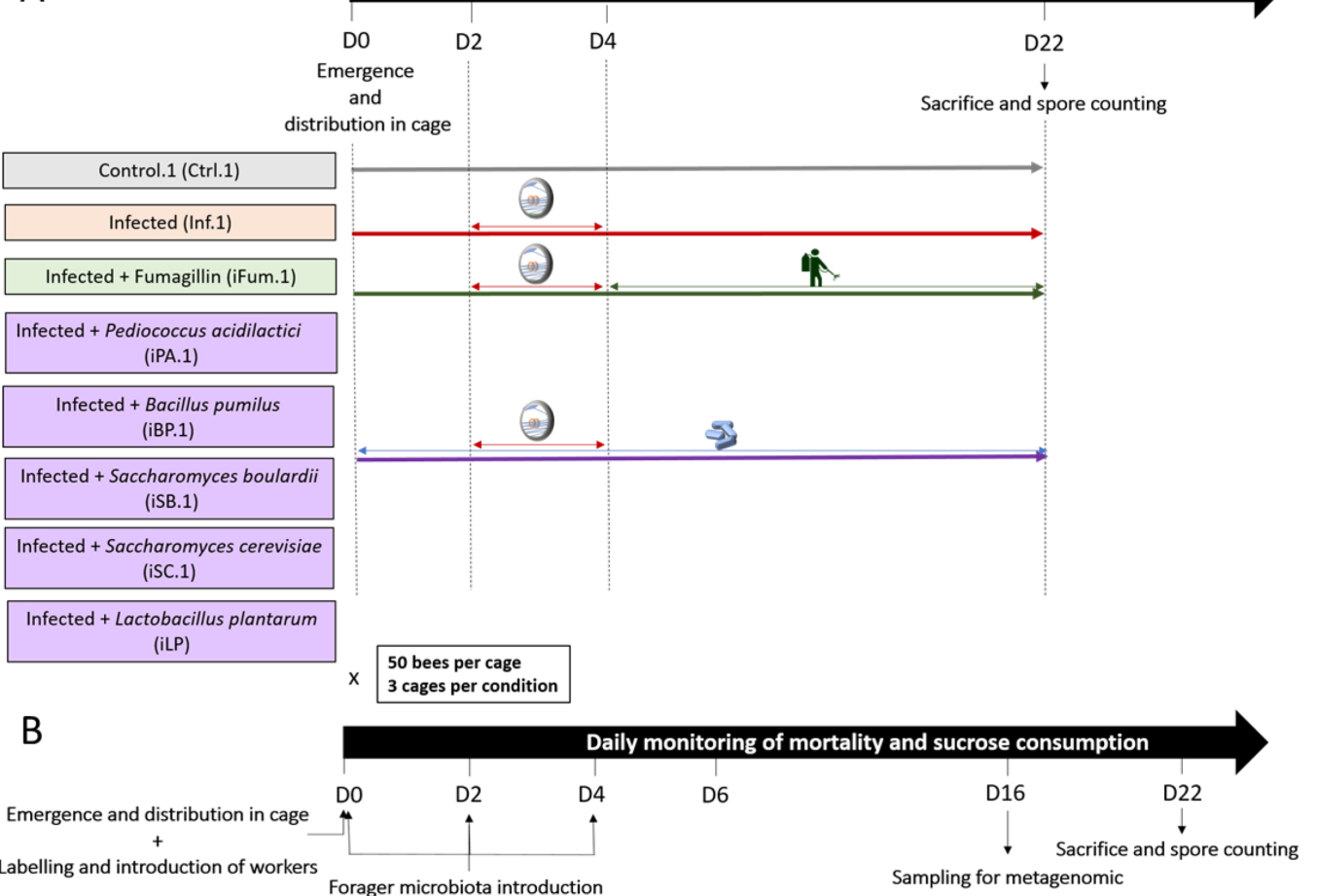

\begin{tabular}{|c|}
\hline Control.1 (Ctrl.2) \\
\hline Thiamethoxam + Boscalid (ThBo.2) \\
\hline Pediococcus acidilactici (PA.2) \\
\hline Saccharomyces boulardii (SB.2) \\
\hline
\end{tabular}

\begin{tabular}{|c|}
\hline $\begin{array}{c}\text { Thiamethoxam + Boscalid }+ \\
\text { Pediococcus acidilactici (ThBoPA.2) }\end{array}$ \\
\hline $\begin{array}{c}\text { Thiametoxam + Boscalid }+ \\
\text { Saccharomyces boulardii (ThBoSB.2) }\end{array}$ \\
\hline
\end{tabular}

Infected + Saccharomyces cerevisiae

Infected + Saccharomyces cerevisiae
(iSC. 2 )

Infected + Bacillus pumilus (iBP. 2)

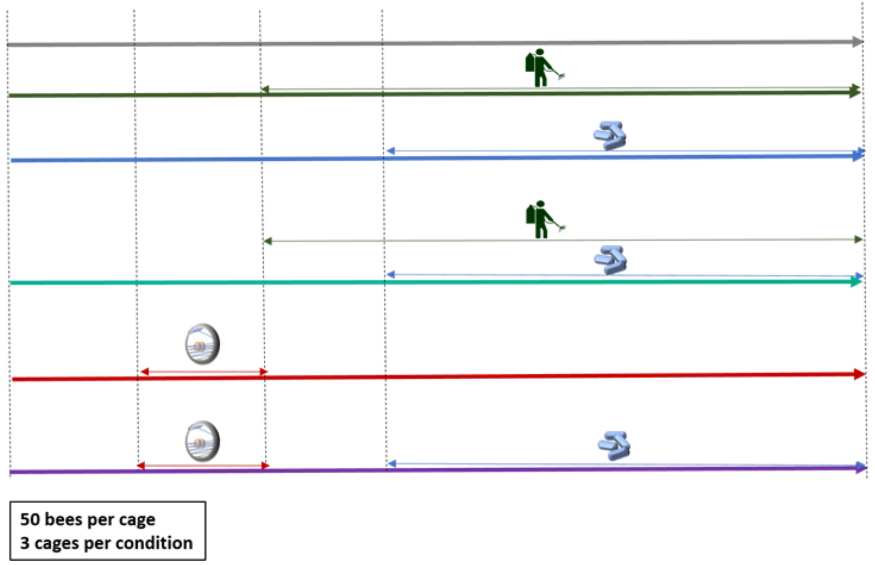

\begin{tabular}{ll}
\hline Collective infection by $N$. ceranae \\
Treatment with pesticides or fumagillin \\
\hline
\end{tabular}

Figure 1 


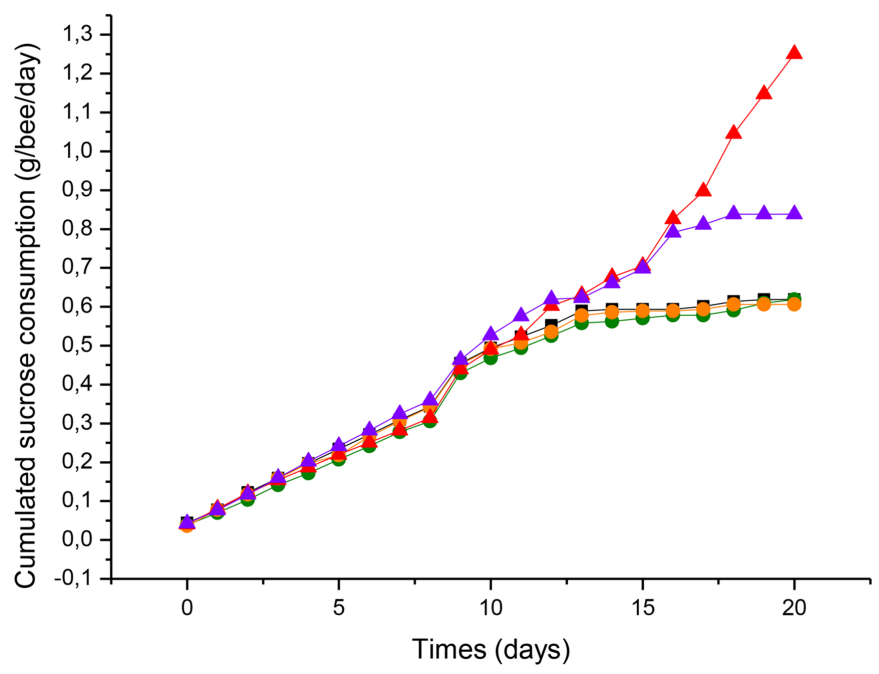

Ctrl.2

ThBo.2

ThBoPA.2

Inf.2

InfPA.2

Times (days)

Figure 2 


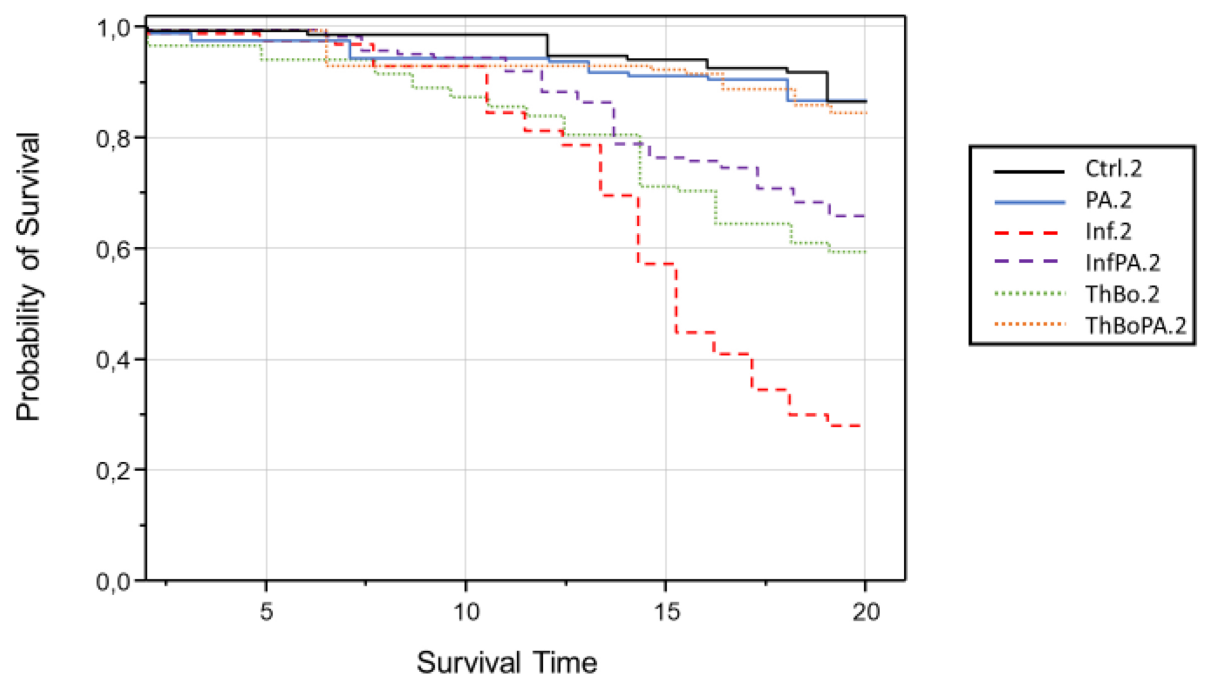

Figure 3 


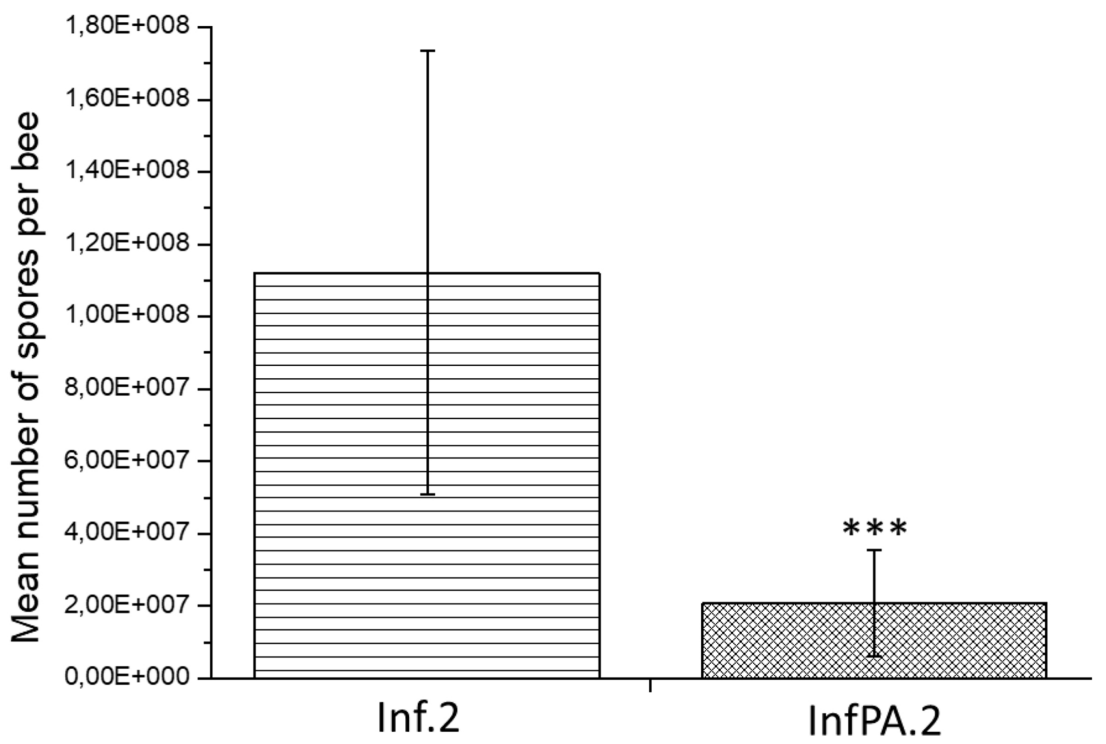

Figure 4 


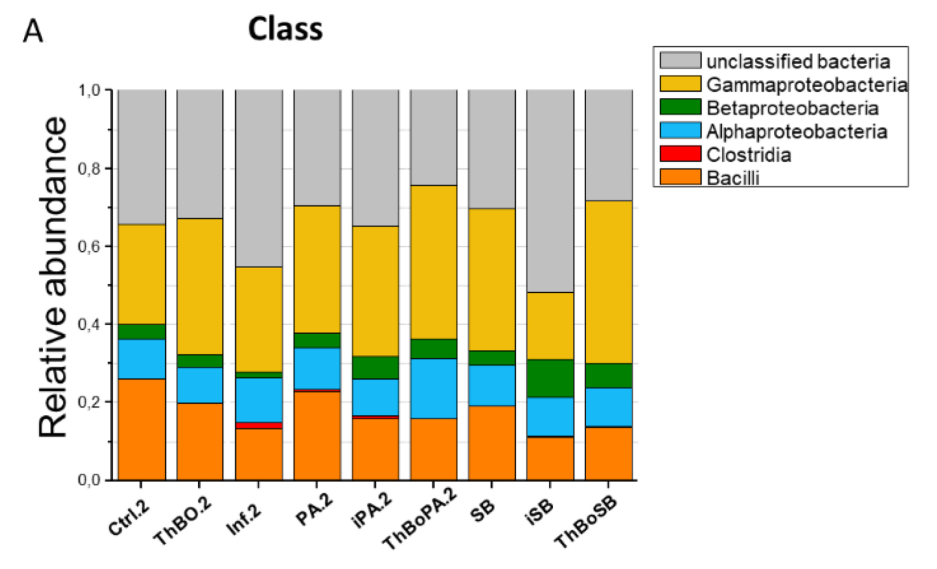

Order

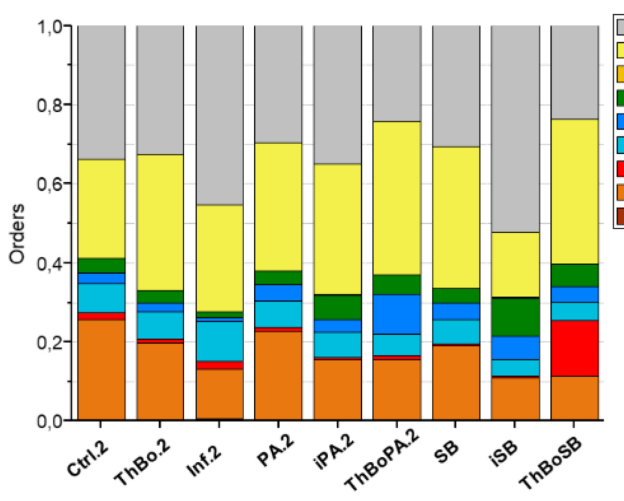

unclassified bacteria Orbales

Enterobacteriales

Neisseriales

Rhodospirillales

Rhizobiales

Clostridiales

Lactobacillales

Bacillales

Figure 5 
A

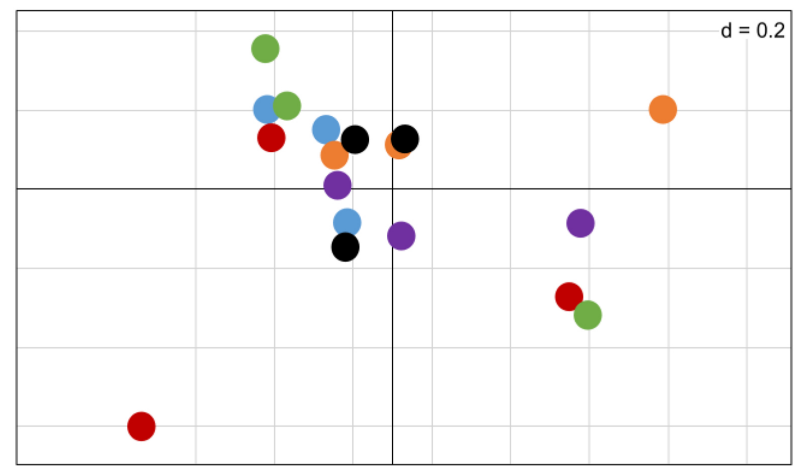

B

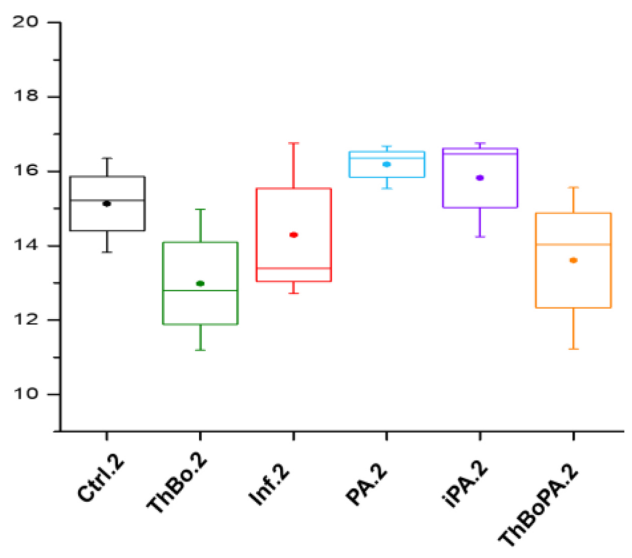

Figure 6 


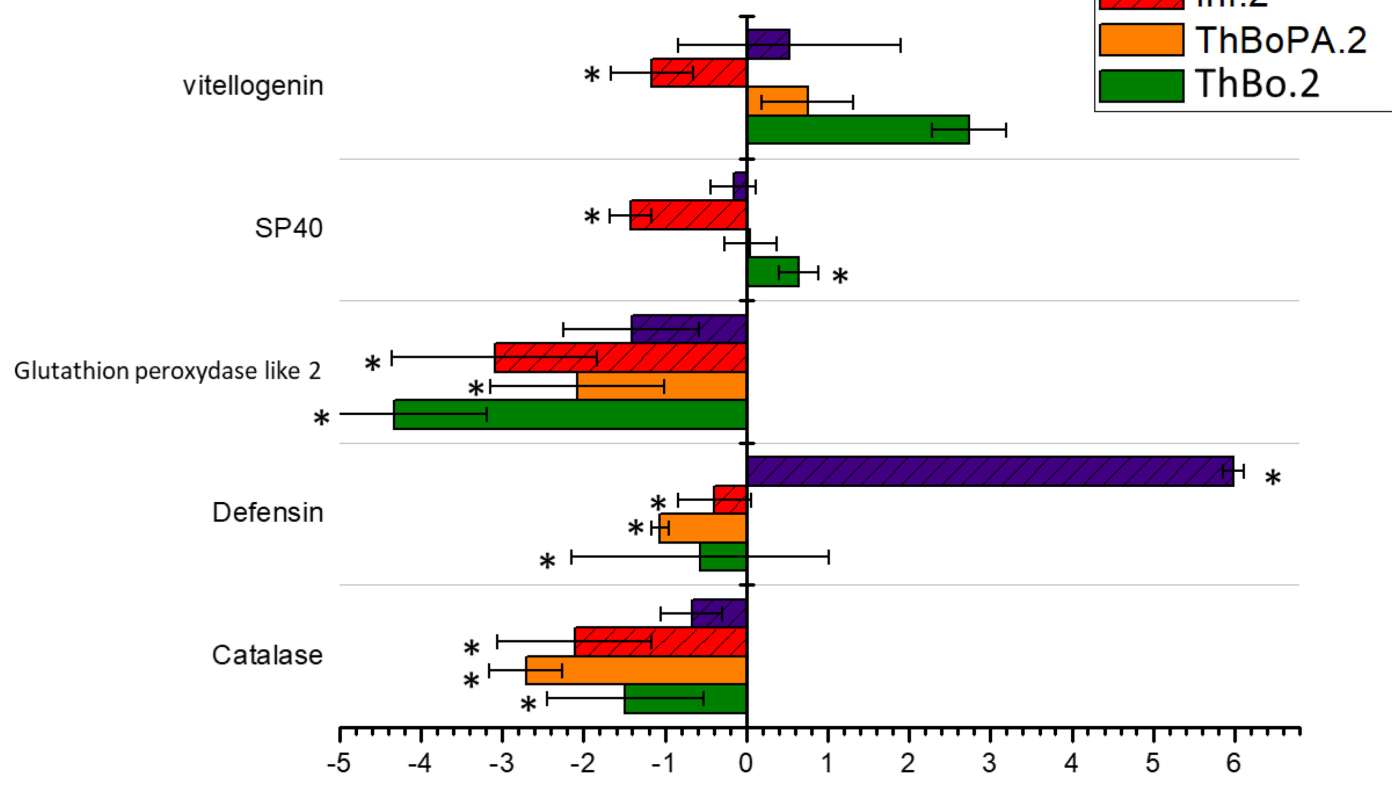

Figure 7 